\title{
Empirical validation of models to compute solar irradiance on inclined surfaces for building energy simulation
}

P.G. Loutzenhiser ${ }^{1,2}$, H. Manz ${ }^{1}$, C. Felsmann ${ }^{3}$, P.A, Strachan ${ }^{4}$, G.M. Maxwell ${ }^{2}$

${ }^{1}$ Swiss Federal Laboratories for Materials Testing and Research (EMPA), Laboratory for Applied Physics in Buildings, CH-8600 Duebendorf, Switzerland

${ }^{2}$ Iowa State University, Department of Mechanical Engineering, Ames, IA 50011 USA

${ }^{3}$ Technical University of Dresden, Institute of Thermodynamics and Building Systems Engineering, D01062 Dresden, Germany

${ }^{4}$ University of Strathclyde, Department of Mechanical Engineering, ESRU, Glasgow G1 1XJ, Scotland

Keywords: Solar radiation models; Empirical validation; Building energy simulation; Uncertainty analysis

\section{Abstract}

Accurately computing solar irradiance on external facades is a prerequisite for reliably predicting thermal behavior and cooling loads of buildings. Validation of radiation models and algorithms implemented in building energy simulation codes is an essential endeavor for evaluating sorargain models. Seven solar radiation models implemented in four building energy simulation codes setelinvestigated: 1) isotropic sky, 2) Klucher 3) Hay-Davies, 4) Reindl, 5) Muneer, 6) 1987 Perez, and (\$ 190 Perez models. Solar radiation data from two 25 days period in October and March/April, whichinel huded diverse atmospheric conditions and solar altitudes, measured on the EMPA campus in a suburban area in Duebendorf, Switzerland, were used for validation purposes. Two of the three measured carponents of solar irradiances-global horizontal, diffuse horizontal and direct-normal-were used as inputs for ealculating global irradiance on a south-west façade. Numerous statistical parameters were employed to analyze hourly measured and predicted global vertical irradiances. Mean absolute deviations foribotkperiods were found to be: 1 ) $13.7 \%$ and $14.9 \%$ for the isotropic sky model, 2) $9.1 \%$ for the Hay-Dayies model, 3) $9.4 \%$ for the Reindl model, 4) $7.6 \%$ for the Muneer model, 5) $13.2 \%$ for the Klucher mode 6) $9.0 \%, 7.7 \%, 6.6 \%$, and $7.1 \%$ for the 1990 Perez models, and 7) $7.9 \%$ for the 1987 Perez model. Detailed sensitivity analyses using Monte Carlo and Fitted Effects for N-way Factorial analyses were Aplifect to assess how uncertainties in input parameters propagated through one of the building energ on the lation codes and impacted the output parameter. The implications of deviations in computed solar iridiances on predicted thermal behavior and cooling load of buildings are discussed.

\section{Introduction}

In the $21^{\text {st }}$ centures engineers and architects are relying increasingly on building energy simulation codes to design more engry-efficient buildings. One of the common traits found in new commercial buildings across Europe and the United States is construction with large glazed façades. Accurate modeling of the impact of solar gains through glazing is imperative especially when simulating the thermal behavior of these buildings. Empirical validations of solar gain models are therefore an important and necessary endeavor to provide confidence to developers and modelers that their respective algorithms simulate reality.

A preliminary step in assessing the performance of the solar gain models is to examine and empirically validate models that compute irradiance on exterior surfaces. Various radiation models for inclined surfaces have been proposed - some of which have been implemented in building energy simulation codes - which include isotropic models (Hottel and Woerz, 1942 as cited by Duffie and Beckman, 1991; Liu and Jordan 1960; Badescu, 2002), anisotropic models (Perez et al.,1990, 1986; Gueymard, 1987; Robledo and Soler, 2002; Li et al., 2002; Olmo et al., 1999) and models for a clear sky (Robler and Soler, 2002). Comparisons and modifications to these models and their applications to specific regions in the world have also been undertaken (Behr, 1997; Ruiz et al., 2002; Remund et. al., 1998). 


\begin{tabular}{|c|c|c|c|}
\hline \multicolumn{4}{|c|}{ Nomenclature } \\
\hline$A$ & anisotropic index, - & $i, j$ & $\begin{array}{l}\text { indices the } n \text {-factorial study the represent different } \\
\text { levels of input parameters }\end{array}$ \\
\hline$B$ & radiation distribution index, - & $\overline{O U}$ & $\begin{array}{l}\text { average overall uncertainty calculated for } 95 \% \\
\text { credible limits, }, \mathrm{W} / \mathrm{m}^{2}\end{array}$ \\
\hline$a, b$ & $\begin{array}{l}\text { terms that account for the incident angle on the } \\
\text { sloped surface, - }\end{array}$ & $s$ & sample standard deviation, $\mathrm{W} / \mathrm{m}^{2}$ \\
\hline$D_{\max }$ & $\begin{array}{l}\text { maximum difference between experimental and } \\
\text { predicted values for a given array, } \mathrm{W} / \mathrm{m}^{2}\end{array}$ & $R_{b}$ & $\begin{array}{l}\text { variable geometric factor which is a ratio of tilted and } \\
\text { horizontal solar beam irradiance }\end{array}$ \\
\hline$D_{\min }$ & $\begin{array}{l}\text { minimum difference between experimental and } \\
\text { predicted values for a given array, } \mathrm{W} / \mathrm{m}^{2}\end{array}$ & $u$ & $\begin{array}{l}\text { is the specific effects from the } n \text {-factorial study, } \\
\mathrm{W} / \mathrm{m}^{2}\end{array}$ \\
\hline$D_{\text {rms }}$ & $\begin{array}{l}\text { root mean squared difference between experimental } \\
\text { and predicted values for a given array, } \mathrm{W} / \mathrm{m}^{2}\end{array}$ & $T F$ & tilt factor, - \\
\hline$D_{95 \%}$ & $\begin{array}{l}\text { Ninety-fifth percentile of the differences between } \\
\text { experimental and predicted values for a given array, } \\
\mathrm{W} / \mathrm{m}^{2}\end{array}$ & $U R$ & $\begin{array}{l}\text { computed hourly uncertainty ratio for comparing } \\
\text { overall performance of a given modet }\end{array}$ \\
\hline$d$ & $\begin{array}{l}\text { estimated error quantity provided by the } \\
\text { manufacturer, units vary }\end{array}$ & $\overline{U R}$ & average uncertainty rat \\
\hline$F_{1}$ & circumsolar coefficient, - & $U R_{\max }$ & maximum uncertainty râtio, - \\
\hline$F_{2}$ & brightness coefficient, - & $U R_{\min }$ & minimum uncertajetoratio, - \\
\hline$F^{\prime}$ & clearness index, - & $\bar{x}$ & arithmetic mean given array of data, $\mathrm{W} / \mathrm{m}^{2}$ \\
\hline & & $\begin{array}{l}x_{\min } \\
x_{\max }\end{array}$ & 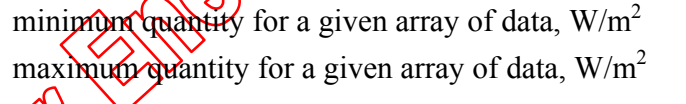 \\
\hline $\begin{array}{l}f_{11}, f_{12} \\
f_{13}, f_{21} \\
f_{22}, f_{23}\end{array}$ & $\begin{array}{l}\text { statistically derived coefficients derived from } \\
\text { empirical data for specific locations as a function of } \\
\varepsilon,-\end{array}$ & & \\
\hline$I_{b n}$ & direct-normal solar irradiance, $\mathrm{W} / \mathrm{m}^{2}$ & & absorptance, $\%$ \\
\hline$I_{h}$ & global horizontal solar irradiance, $\mathrm{W} / \mathrm{m}^{2}$ & & normal absorptance, $\%$ \\
\hline$I_{h, b}$ & $\begin{array}{l}\text { direct-normal component of solar irradiance on the } \\
\text { horizontal surface, } \mathrm{W} / \mathrm{m}^{2}\end{array}$ & $\alpha_{s}$ & solar altitude angle, ${ }^{\circ}$ \\
\hline$I_{h, d}$ & global diffuse horizontal solar irradiance. $\mathrm{W} \mathrm{m}^{2}$ & $\beta$ & surface tilt angle from horizon, ${ }^{\circ}$ \\
\hline$I_{o n}$ & direct extraterrestrial normal irradiance. $\mathrm{W} / \mathrm{m}^{2}$ & $\Delta$ & sky condition parameter for brightness \\
\hline$I_{T}$ & solar irradiance on the tilted suiface, W/m & $\varepsilon$ & sky condition parameter for clearness \\
\hline$I_{T, b}$ & $\begin{array}{l}\text { direct-normal (beam } \text { domponent of solar irradiance } \\
\text { on the tilted suntace, } W / \mathrm{m}^{2}\end{array}$ & $\phi_{b}$ & building azimuth, ${ }^{\circ}$ \\
\hline$I_{T, d}$ & $\begin{array}{l}\text { diffuse component of solar irradiance on the tilted } \\
\text { surface, W/m }\end{array}$ & $\theta$ & incident angle of the surface, ${ }^{\circ}$ \\
\hline$I_{T, d, i s o}$ & $\begin{array}{l}\text { isotropic diffuse component of solar irradiance on } \\
\text { the tilted surface, } \mathrm{W} / \mathrm{m}^{2}\end{array}$ & $\theta_{z}$ & zenith angle, $^{\circ}$ \\
\hline$I_{T, d, c s}$ & $\begin{array}{l}\text { circumsolar diffuse component of solar irradiance } \\
\text { on the tilted surface, } \mathrm{W} / \mathrm{m}^{2}\end{array}$ & $\xi$ & input parameter n-way factorial, units vary \\
\hline$I_{T, d, h b}$ & $\begin{array}{l}\text { horizontal brightening diffuse component of solar } \\
\text { irradiance on the tilted surface, } \mathrm{W} / \mathrm{m}^{2}\end{array}$ & $\rho$ & hemispherical-hemispherical ground reflectance, - \\
\hline$I_{T, d, g}$ & $\begin{array}{l}\text { reflected ground diffuse component of solar } \\
\text { irradiance on the tilted surface, } \mathrm{W} / \mathrm{m}^{2}\end{array}$ & $\sigma$ & standard deviation n-way factorial, units vary \\
\hline
\end{tabular}

1 In all empirical validations, accounting for uncertainties in the experiment and input parameters is 2 paramount. Sensitivity analysis is a well-established technique in computer simulations (Saltelli et al. 2004, 3 2000; Santer et al., 2003) and has been implemented in building energy simulation codes (Macdonald and 
Strachan, 2001) and empirical validations (Mara et al., 2001; Aude et al., 2000; Fürbringer and Roulet, 1999, 1995; Lomas and Eppel, 1992) for many years. A thorough methodology for sensitivity analysis for calculations, correlation analysis, principle component analysis, and implementation in the framework of empirical validations in IEA-SHC Task 22 are described by Palomo Del Barrio and Guyon (2004; 2003).

In the context of the International Energy Agency's (IEA) SHC Task 34/ ECBCS Annex 43 Subtask C, a series of empirical validations is being performed in a test cell to assess the accuracy of solar gain models in building energy simulation codes with/without shading devices and frames. A thorough description of the proposed suite of experiments, description of the cell, rigorous evaluation of the cell thermophysical properties and thermal bridges, and a methodology for examining results are reported by Manz et al. (2005).

In virtually all building energy simulation applications, solar radiation must be calculated on tilted surfaces. These calculations are driven by solar irradiation inputs or appropriate correction factors and clear sky models. While the horizontal irradiation is virtually always measured, measuring of direct-normal and/or diffuse irradiance adds an additional level of accuracy (Note: In the absence of the latter two parameters, models have to be used to split global irradiation into direct and diffuse).

The purpose of this work is to validate seven solar radiation models on tilted surfaces thatareinplemented in widely used building energy simulation codes including: EnergyPlus(2005), DOE-2.2e (2002), ESP-r (2005), and TRNSYS-TUD (2005). The seven models examined include:

- Isotropic sky (Hottel and Woertz, 1942 as cited by Duffie and Beckman, 199013

- Klucher (1979)

- Hay-Davies(1980)

- Reindl (1990)

- Muneer (1997)

- Perez (1987)

- Perez (1990)

Two of three measured irradiance components ture rused in each simulation and predictions of global vertical irradiance on a façade oriented 29 gest of South were compared with measurements. Particular emphasis was placed on quantifying kow orncertainty in the input parameters-direct-normal, diffuse and horizontal global solar irradiance as as ground reflectance and surface azimuth angle-propagated through radiation calculation algorithios and impacted the global vertical irradiance calculation. Sensitivity analyses were performed using (berth the Monte Carlo Analysis (MCA) and Fitted Effects for N-way Factorials.

\section{Solar Radiation $\mathbf{M}$ Fod dels}

Total solar irradingelon a tilted surface can be divided into two components: 1) the beam component from direct irradiation of the tilted surface and 2) the diffuse component. The sum of these components equates to the total irradiance on the tilted surface and is described in Equation 1.

$$
I_{T}=I_{T, b}+I_{T, d}
$$

Studies of clear skies have led to a description of the diffuse component being composed of an isotropic diffuse component (uniform irradiance from the sky dome), circumsolar diffuse component (resulting from the forward scattering of solar radiation and concentrated in an area close to the sun), horizon brightening component (concentrated in a band near the horizon and most pronounced in clear skies), and a reflected component that quantifies the radiation reflected from the ground to the tilted surface. A more complete version of Equation 1 containing all diffuse components is given in Equation 2. 
1 For a given location (longitude, latitude) at any given time of the year (date, time) the solar azimuth and altitude can be determined applying geometrical relationships. Therefore, the incidence angle of beam radiation on a tilted surface can be computed. The models described in this paper all handle beam radiation in this way so the major modeling differences are calculations of the diffuse radiation. An overview of solar radiation modeling used for thermal engineering is provided in numerous textbooks including Duffie and Beckman (1991) and Muneer (1997). Solar radiation models with different complexity which are widely implemented in building energy simulation codes will be briefly described in the following sections.

\subsection{Isotropic Sky Model}

The isotropic sky model (Hottel and Woerz, 1942 as cited by Duffie and Beckman, 1991; Liu and Jordan, 1960 ) is the simplest model that assumes all diffuse radiation is uniformly distributed over the sky dome and that reflection on the ground is diffuse. For surfaces tilted by an angle $\beta$ from the horizontal plane, total solar irradiance can be written as

$I_{T}=I_{h, b} R_{b}+I_{h, d}\left(\frac{1+\cos \beta}{2}\right)+I_{h} \rho\left(\frac{1-\cos \beta}{2}\right)$

Circumsolar and horizon brightening parts (Eq. 2) are assumed to be zero.

\subsection{Klucher Model}

Klucher (1979) found that the isotopic model gave good results for overcast skies but underestitnates irradiance under clear and partly overcast conditions, when there is increased intensity near the horizon and in the circumsolar region of the sky. The model developed by Klucher gives the totalinadiation on a tilted plane shown in Equation 4.

$I_{T}=I_{h, b} R_{b}+I_{h, d}\left(\frac{1+\cos \beta}{2}\right)\left[1+F^{\prime} \sin ^{3}\left(\frac{\beta}{2}\right)\right]\left[1+F^{\prime} \cos ^{2} \vartheta \sin ^{3} \vartheta_{2}\right]$

$F^{\prime}$ is a clearness index given by Equation 5.

$F^{\prime}=1-\left(\frac{I_{h, d}}{I_{h}}\right)^{2}$

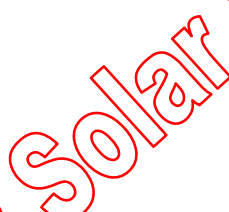

The first of the modifying factors in the sky diffuse conn second takes into account the effect of circumsolar sadiation. Under overcast skies, the clearness index F' becomes zero and the model reduces to the isotrapiamodel.

\subsection{Hay-Davies Model}

In the Hay-Davies model, diffuse radifion from the sky is composed of an isotropic and circumsolar component (Hay and Davies, 198 and horizon brightening is not taken into account. The anisotropy index A defined in Equation 6 represents the transmittance through atmosphere for beam radiation.

$A=\frac{I_{b n}}{I_{o n}}$

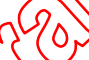

The anisotropy index is used to quantify a portion of the diffuse radiation treated as circumsolar with the remaining portion of diffuse radiation assumed isotropic. The circumsolar component is assumed to be from the sun's position. The total irradiance is then computed in Equation 7.

$I_{T}=\left(I_{h, b}+I_{h, d} A\right) R_{b}+I_{h, d}(1-A)\left(\frac{1+\cos \beta}{2}\right)+I_{h} \rho\left(\frac{1-\cos \beta}{2}\right)$

Reflection from the ground is dealt with as for the isotropic model.

\subsection{Reindl Model}

In addition to isotropic diffuse and circumsolar radiation, the Reindl model also accounts for horizon brightening (Reindl et al, 1990a; Reindl et al, 1990b) and employs the same definition of the anisotropy 
index $\mathrm{A}$ as described in Equation 6. The total irradiance on a tilted surface can then be calculated using Equation 8.

$I_{T}=\left(I_{h, b}+I_{h, d} A\right) R_{b}+I_{h, d}(1-A)\left(\frac{1+\cos \beta}{2}\right)\left[1+\sqrt{\frac{I_{h, b}}{I_{h}}} \sin ^{3}\left(\frac{\beta}{2}\right)\right]+I_{h} \rho\left(\frac{1-\cos \beta}{2}\right)$

Reflection on the ground is again dealt with as for the isotropic model. Due to the additional term in Equation 8 representing horizon brightening, the Reindl model provides slightly higher diffuse irradiances than the Hay-Davies model.

\subsection{Muneer Model}

Muneer's model is summarized by Muneer (1997). In this model the shaded and sunlit surfaces are treated separately, as are overcast and non-overcast conditions of the sunlit surface. A tilt factor $T_{F}$ representing the ratio of the slope background diffuse irradiance to the horizontal diffuse irradiance is calculated from Equation 9.

$T_{F}=\left(\frac{1+\cos \beta}{2}\right)+\frac{2 B}{\pi(3+2 B)}\left[\sin \beta-\beta \cos \beta-\pi \sin ^{2} \frac{\beta}{2}\right]$

For surfaces in shade and sunlit surfaces under overcast sky conditions, the total radiation on a tilted plane is given in Equation 10.

$$
I_{T}=I_{h, b} R_{b}+I_{h, d} T_{F}+I_{h} \rho\left(\frac{1-\cos \beta}{2}\right)
$$

Sunlit surfaces under non-overcast sky conditions can be calculated using Equation 11.

$$
I_{T}=I_{h, b} R_{b}+I_{h, d}\left[T_{F}(1-A)+A R_{b}\right]+I_{h} \rho\left(\frac{1-\cos \beta}{2}\right)
$$

The values of the radiation distribution index B depend on the particular syand animuthal conditions, and the location. For European locations, Muneer recommends fixed values for the cases of shaded surfaces and sun-facing surfaces under an overcast sky, and a function of the anisotropic index for non-overcast skies.

\subsection{Perez Model}

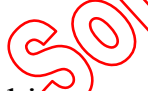

Compared with the other models described, the Perez model is more computationally intensive and represents a more detailed analysis of the isotropic diffuse, circumsolar and horizon brightening radiation by using empirically derived coefficients (Perez et al, 1990). The total irradiance on a tilted surface is given by Equation 12.

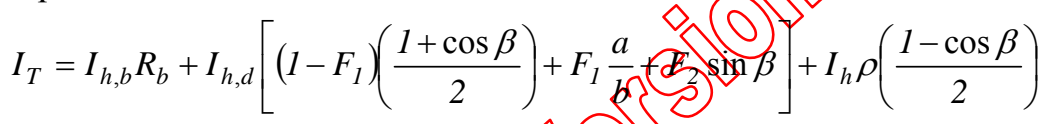

Here, $F_{1}$ and $F_{2}$ are circumsolar and horizon brightness coefficients, respectively, and $a$ and $b$ are terms that take the incidence angle of thessun on the considered slope into account. The terms $a$ and $b$ are computed using Equations 13 and 14, respectively.

$32 a=\max (0, \cos \theta)$

$b=\max \left(\cos 85, \cos \theta_{z}\right)$

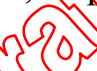

34 The brightness coefficients $F_{1}$ and $F_{2}$ depend on the sky condition parameters clearness $\varepsilon$ and brightness $\Delta$.

$\varepsilon=\frac{\frac{I_{h, d}+I_{n}}{I_{h, d}}+5.535 \cdot 10^{-6} \theta_{z}^{3}}{1+5.535 \cdot 10^{-6} \theta_{z}^{3}}$

$\Delta=m \frac{I_{h, d}}{I_{o n}}$ 
$F_{1}$ and $F_{2}$ are then computed in Equations 17 and 18, respectively.

$2 \quad F_{1}=\max \left[0,\left(f_{11}+f_{12} \Delta+\frac{\pi \theta_{z}}{180} f_{13}\right)\right]$

$3 \quad F_{2}=f_{21}+f_{22} \Delta+\frac{\pi \theta_{z}}{180} f_{23}$

4

5

6

7

8

9

10

11

12

13

14

15

16

17

18

19

20

21

22

23

24

25

26

27

The coefficient $f_{11}, f_{12}, f_{13}, f_{21}, f_{22}$, and $f_{23}$ were derived based on a statistical analysis of empirical data for specific locations. Two different sets of coefficients were derived for this model (Perez et al, 1990; 1988 as cited by Duffie and Beckman, 1991). An earlier version of the model with different coefficients (Perez 1987) was also included in this analysis.

\section{Facility and Measurements}

\subsection{Test Site and Setup}

The solar radiation measurements were performed on the EMPA campus located in Duebendors Switzerland (Longitude $8^{\circ} 36^{\prime} 55^{\prime \prime}$, Latitude $\left.47^{\circ} 24^{\prime} 12^{\prime \prime}\right)$. Figure 1 shows the facility which was designed to poeasure solar gains of transparent façade components; a detailed description of facility is provided by ranz et al. (2005). For this study, only the pyranometers and the pyrheliometer at the facility were usea (Figures 1 and 2). For the diffuse measurements, a shading disk was mounted in front of the pyranomerer hkith the same solid angle as the pyrheliometer that blocked out the beam irradiance component (Figure 2 . Mn order to evaluate the robustness of various radiation models, two 25 day periods were studied to eongpare predicted irradiance on the tilted façade with measured data that were recorded by a pyranomeret mounted on the vertical surface $\left(29^{\circ}\right.$ West of South) of the test cell. The dates of the first and second getrods were October 2 to October 26, 2004 and March 22 to April 16, 2005, respectively. Both periodsinctude a range of different atmospheric conditions and solar positions. The solar radiation data were acalumed for $600 \mathrm{~h}$ for each period.

\subsection{Solar Irradiance}

Table 1 indicates measured parameters, type of instrument used and accuracies of sensors specified by the manufacturers. To verify the accuracy of the inst oumentation, the global horizontal irradiance can be calculated using solar position and direct-pontatand horizontal diffuse irradiance shown in Equation 19. $\mathrm{I}_{\mathrm{h}}=\mathrm{I}_{\mathrm{b}, \mathrm{n}} \sin \alpha_{\mathrm{s}}+\mathrm{I}_{\mathrm{h}, \mathrm{d}}$

The differences between global horixgntal irradiance measured and computed based on direct-normal (beam) and horizontal diffuse irradiance were analyzed. Using the experimental uncertainties described in Table 1, $95 \%$ credible limits were cate 1 thed for the measured global horizontal irradiance using manufacturer's error and for the computed glogal (4) uniform distributions folesner, 1998). From these comparisons, the $95 \%$ credible limits from the calculated and measured global horizontal irradiance for Periods 1 and 2 were found to overlap $78.0 \%$ and $70.1 \%$ of the time, respectively; these calculations were only performed when the sun was up $\left(\alpha_{S}>0\right)$. Careful examination of these results reveals that the discrepancies occurred when the solar altitude angles and irradiance were small or the solar irradiance were very large (especially for Period 2). Linear regression analysis was used to compare the computed and measured global irradiances. The results from this analysis are shown for Periods 1 and 2 in Figures $3 \mathrm{a}$ and 3b, respectively. The differences between calculated and measured quantities are apparent from the slopes of lines. These results reveal a slight systematic underprediction by roughly $3 \%$ of global horizontal irradiance when calculating it from the beam and diffuse horizontal irradiance components.

\subsection{Ground Reflectance}

The importance of accurately quantifying the albedo in lieu of relying on default values is discussed in detail by Ineichen et al. (1987). Therefore, in order to have a well-defined and uniform ground reflectance, artificial green turf was installed in front of the test cell to represent a typical outdoor surface (Figure 1). 
Reflectance of a sample of the artificial turf was measured at almost perpendicular $\left(3^{\circ}\right)$ incident radiation in the wavelength interval between $250 \mathrm{~nm}$ and $2500 \mathrm{~nm}$ using an integrating sphere (Figure 4) which could not be employed for angular dependent measurements. Specular components of the reflectance were measured at incident angles of $20^{\circ}, 40^{\circ}$, and $60^{\circ}$ and were found to be less than $1 \%$; therefore the surface was considered to be a Lambertian surface (Modest, 2003). Integral values for reflectance were determined according to EN 410 (1998) by means of GLAD software (2002). Hemispherical-hemispherical reflectance was then determined at each wavelength assuming an angular dependent surface absorptance as shown in Equation 20 (from Duffie and Beckman, 1991).

$\frac{\alpha(\theta)}{\alpha_{n}}= \begin{cases}1+2.0345 \times 10^{-3} \theta-1.99 \times 10^{-4} \theta^{2}+5.324 \times 10^{-6} \theta^{3}-4.799 \times 10^{-8} \theta^{4} & 0^{\circ} \leq \theta \leq 80^{\circ} \\ -0.064 \theta+5.76 & 80^{\circ} \leq \theta \leq 90^{\circ}\end{cases}$

Equation 21 was used to calculate the hemispherical-hemispherical reflectance.

$\rho=2 \int_{0^{\circ}}^{90^{\circ}}(1-\alpha(\theta)) \sin (\theta) \cos (\theta) d \theta$

This integral was evaluated numerically using the Engineering Equation Solver (Klein, 2004). The computed solar ground reflectance (Table 2) corresponds well with albedo measurements described by Ineichenef all. (1987).

\section{Simulations}

The incident (global vertical) irradiance on the exterior façade for all the building energysingulation codes was a function of the solar irradiance and ground reflectance. Four building energ \& symulation codes, EnergyPlus, DOE-2.1e, ESP-r and TRNSYS-TUD, which included seven differention models were evaluated for both periods.

EnergyPlus version 1.2.2 uses the 1990 Perez model. For the simulation 4 measured direct-normal and diffuse horizontal solar irradiance were used as inputs in 10 minute timesteps. DOE-2.1e also uses a Perez 1990 model to calculate irradiance on a tilted façade (Buehl, 2005) witiphourly inputs of direct-normal and global horizontal solar irradiance. Both EnergyPlus and DOE 2. He assumed a constant annual direct-normal extraterrestrial irradiation term (they do not factor in the entiptical orbit of the earth around the sun). TRNSYS-TUD allows the user to select from four modelsand various inputs for solar irradiance. For these experiments, the Isotropic, Hay-Davies, Reindd, arad Perez 1990 model were used with inputs of measured direct normal and global horizontal irradiancej inputs to the models were in 1 hour time steps. An average annual extraterrestrial irradiation termas also assumed for the Perez, Reindl, and Hay-Davies models. ESP-r has the Perez 1990 mode@ as its default, but other models are available to the user, namely the Isotropic, Klucher, Muneer and Peres $\$ 87$ models. Measured 6 minutely averaged data were input to the program. The program takes infosaccount variations in the extraterrestrial radiation in the Perez and Muneer models. It is also possible to use direct normal plus diffuse horizontal irradiation, or global horizontal plus diffuse horizontal irradiation as Grpputs to ESP-r; for this study, only the direct normal and diffuse horizontal inputs were studied.

\section{Sensitivity Analysis}

Sensitivity studies are an important component in thorough empirical validations; such studies were therefore also performed. The uncertainties in the input parameters were taken from information provided by the manufacturers (Table 1). The error in the ground reflectance calculation (models and measurements combined) was estimated as $5 \%$ (see Table 2 ) and $\pm 1^{\circ}$ for the building azimuth. Uniform distributions were assumed for estimated uncertainties and quantities provided by manufacturers (Glesner, 1998). Although all the codes perform solar angle calculations, uncertainties were not assigned to the cell locations (latitude and longitude). Two types of sensitivity analysis were performed for this project in EnergyPlus which included

47 Fitted Effects for N-way Factorials and MCA. For these analyses the source code was not modified, but 
rather a "wrap" was designed to modify input parameters in the weather file and the input file for EnergyPlus in MatLab 7.0 (2004). A Visual Basic program was written to create a command line executable program to run the "WeatherConverter" program and the "RunEplus.bat" program was run from the MatLab programs. Output from each run was recorded in output files. A flowchart for this process is depicted in Figure 6.

\subsection{Fitted Effects for $N$-way Factorials}

A Fitted Effects N-way Factorial method was used to identify the impact of uncertainties in various parameters on the results (Vardeman and Jobe, 2001). The parameters that were varied for this study included: ground reflectance, direct-normal irradiance, global horizontal irradiance (which was an unused parameter in EnergyPlus), and diffuse irradiance. Therefore, for this study a fitted effects for a three-way factorial analysis was performed. The first step in this process is to run a one-way factorial shown in Equation 22 varying each parameter.

$u_{i}=\phi\left(\xi_{i}+\sigma_{i}\right)-\phi\left(\xi_{i}\right)$

14 For uniform distributions, the standard deviation is estimated in Equation 23.

$\sigma_{i}=\frac{d}{\sqrt{3}}$

The two-way factorials were estimated using Equation 24. Additional levels of interactions were considered but were found to be negligible.

$u_{i j}=\phi\left(\xi_{i}+\sigma_{i}, \xi_{j}+\sigma_{j}\right)-\left(\phi\left(\xi_{i}, \xi_{j}\right)+u_{i}+u_{j}\right) \quad \mathrm{i} \neq \mathrm{j}$

The overall uncertainty was estimated using the quadrature summation shown in Equation 25.

$u=\sqrt{\sum u_{i}^{2}+\sum u_{i j}^{2}}$

This analysis assumes a localized linear relationship where the function is evaluated. To fonfifirm this assumption, estimates were made by forward differencing $\left(\xi_{i}+\sigma_{i}\right)$ and backward differeneting $\left(\xi_{i}-\sigma_{i}\right)$. The individual factorials can also be analyzed to assess their impact. In Table 3, the resuliks from this analysis averaged over the entire test $\left(\alpha_{S}>0\right)$ are shown for both forward and backn ward differencing. Looking at the results from forward and backward difference, the assumed localized lineat retationship seems reasonable but may lead to minor discrepancies that are discussed later.

\subsection{Monte Carlo Analysis}

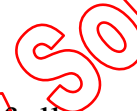

The Monte Carlo method can be used to analyze the impact of all uncertainties simultaneously by randomly varying input parameters and performing multiple evaluations of the output parameter(s). When setting up the analysis, the inputs are modified according to a probability density function (pdf) and, after numerous iterations, the outputs are assumed to be Gaussian (normal) by the Central Limit Theorem. The error is estimated by taking the standard deviation of the nuttiple evaluations at each time step. MatLab 7.0 can be used to generate random numbers according togaussian, uniform, and many other distributions. A comprehensive description and the undergyng theory behind the Monte Carlo Method are provided by Fishman (1996) and Rubinstein (1981)

\subsubsection{Sampling}

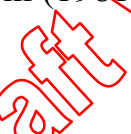

For this study, Latin heperese sampling was used. In this method, the range of each input factor is divided into equal probability intervals based on the number of runs of the simulation; one value is then taken from each interval. When applying this method for this study given parameters with non-uniform distributions, the intervals were defined using the cumulative distribution function and then one value was selected from each interval assuming a uniform distribution (again this was simplified in using MatLab because the functions were part of the code). This method of sampling is better when a few components of input dominate the output (Saltelli et al., 2000). For this study, the input parameters were all sampled from a uniform distribution. Previous studies have shown that after 60-80 there are only slight gains in accuracy (Fürbringer and Roulet, 1995), but 120 runs were used to determine uncertainty. The average overall uncertainties $\left(\alpha_{S}>0\right)$ for Periods 1 and 2 were $2.35 \mathrm{~W} / \mathrm{m}^{2}$ and $2.87 \mathrm{~W} / \mathrm{m}^{2}$, respectively; the results 
corresponded well with the fitted effects models. The results at any given time step are discussed in the next section.

\subsubsection{Analysis of Output}

It can be shown that despite the pdf's for input parameters, the output parameters will always have a Gaussian distribution (given a large enough sample and sufficient number of inputs) by the Central Limit Theorem; therefore a Lilliefore Test for goodness of fit to normal distribution was used to test significance at $5 \%$ (when $\alpha_{S}>0$ ). Using this criterion, $27.5 \%$ and $11.5 \%$ of the outputs from Periods 1 and 2, respectively, were found not to be normally distributed. A careful study of these results reveals that the majority (not all) of these discrepancies occurred when the direct-normal irradiance is small or zero. This may be due to the proportional nature of the uncertainties used for these calculations. At low direct-normal irradiances, the calculation becomes a function of only two inputs rather than three, which could make the pdf for the output parameter more susceptible to the individual pdf's of the input parameters, which for these cases were uniform distributions.

\subsection{Estimated Uncertainties}

Estimates for uncertainties were obtained from both Fitted Effects for N-way Factorial and MCA. From these analyses, both methods yield similar results. The only discrepancies for both forward and backward differencing were that fitted effects estimates are sometimes overestimated at several individual time steps. Careful inspection of the individual responses revealed that there was a significant jump in the two-way direct-normal/diffuse response (sometimes in the order of $5 \mathrm{~W} / \mathrm{m}^{2}$ ) that corresponds to odd behavior in the one-way responses. The response for the rest of the time steps was negligible. Additional review shomed that these events do not occur during the same time steps for forward and backward differencing tomas therefore assumed that these discrepancies result from localized non-linearities at these time steps.

\section{Results}

The computed results from the four simulation codes were compared with the measured gh bal vertical irradiance. Comparisons were made using the nomenclature and methodology proposed by Manz et al. (2005). An important term used for comparing the performance of the respective furodels in the codes is the uncertainty ratio. This term was computed at each hour $\left(\alpha_{s}>0\right)$ and is shoyxuin Equation 26. The average, maximum, and minimum quantities are summarized in the statistical andyes for each test. Ninety-five percent credible limits were calculated from the MCA for EnergyPlus and the 95\% credible limits for the experiment were estimated assuming a uniform distribution. The credible limits from EnergyPlus were used to calculate the uncertainty ratios for all the models and codes. For the uncertainty ratio, terms less than unity indicate that the codes are validated with $95 \%$ credibte firnits.

$U R=\frac{|D|}{O U_{\text {Experiment }}+O U_{\text {EnergyPlus }}}$

Tables 4, 5, and 6 show the results from Periods fand 2 and combined periods, respectively. Plots were constructed that depict the global verticah irradiation (hourly averaged irradiance values multiplied by a $1 \mathrm{hr}$ interval) and credible limits. For these pots, 4 he output and $95 \%$ credible limits for a given hour of the day were averaged to provide an overyiect of the performance of each model. Figures 6 to 8 contain results from Periods 1 and 2 and the combined ressults.

\section{Discussion and Conclusions}

The accuracy of the individual radiation models and their implementation in each building energy simulation code for both periods can be accurately assessed from the statistical analyses and the plots from the results section. Figure 6 shows that in the morning, there are both over or under-prediction of the global vertical irradiance by the models for Period 1; in the afternoon the global vertical irradiance are significantly underpredicted. During Period 2, over-predictions from the statistical analysis can be seen in both the morning and the afternoon from Figure 7, which explains results from the statistical analysis. Combining these results 
helps to redistribute the hourly over and under-predictions from each model, but it is still clear all the models performed better during Period 1.

3

Using the average uncertainty ratio as a guide, it can be seen that for both periods none of the models were within overlapping $95 \%$ credible limits. Strictly speaking, none of the models can therefore be considered to be validated within the defined credible limits $((\overline{U R}>1)$. This is partly due to the proportional nature of the error which at vertical irradiance predictions with small uncertainties lead to large hourly uncertainty ratio calculations and the difficulty in deriving a generic radiation model for every location in the world. This is also shown in Figures 6 to 8 where there is very little overlap in the experimental and MCA 95\% credible limits. But the average uncertainty ratio can also be used as a guide to rank the overall performance of the tilted radiation models. The Isotropic model performed the worst during these experiments, which can be expected because it was the most simplistic and did not account for the various individual components of diffuse irradiance. While the Reindl and Hay-Davies model accounted for the additional components of diffuse irradiance (both circumsolar and horizontal brightening for the Reindl and circumsolar for the HayDavies), the Perez formulation - which relied on empirical data to quantify the diffuse componentsprovided the best results for this location and wall orientation. Differences between the Perez models in the four building energy simulation codes can be attributed to solar irradiance input parameters (beam, global horizontal, and diffuse), time steps of the weather measurements, solar angle algorithms, and assumptions made by the programmers (constant direct-normal extraterrestrial radiations for DOE-2.1e and EnergyPlus). For both periods, the assumptions made in the TRNSYS-TUD formulation Perez radiation model performed best. But also from these results, the Muneer model performed quite well without the detail used in the Perez models. In fact, the Muneer model performed better than Perez models formulated in EnergyPlus and DOE2.1e.

The presented results reveal distinct difference between radiation models that will ultimately manifest themselves in the solar gain calculations. Mean absolute deviations in predicting solar irradiance for both time periods were: 1) $13.7 \%$ and $14.9 \%$ for the isotropic sky model, 2) $9.1 \%$ for the Hay-Davies, $379 \%$ for the Reindl, 4) $7.6 \%$ for the Muneer model, 5) $13.2 \%$ for the Klucher, 6) $9.0 \%, 7.7 \%, 6.6 \%$, and $5.10 \%$ for the 1990 Perez, and 7) $7.9 \%$ for the 1987 Perez models. This parameter is a good estimate of the instantaneous error that would impact peak load calculations. The mean deviations calculations or these time periods were: 1) $-5.3 \%$ and $-7.7 \%$ for the isotropic sky model, 2) $-1.1 \%$ for the Hay-Sayies, 3 ) $2.6 \%$ for the Reindl, 4) $2.8 \%$ for the Muneer model, 5) $-6.2 \%$ for the Klucher, 6) $2.6 \%, 50 \%$ Q $50 \%$, and 1.0\% for the 1990 Perez, and 7) 3.5\% for the 1987 Perez models. From this parameter it can be concluded that building energy simulation codes with advanced radiation models are capable of computing total irradiated solar energy on building façades with a high precision for longer time periods (usch as months). Hence, the calculations of building energy consumption with very high prediction accuracy is achievable even in

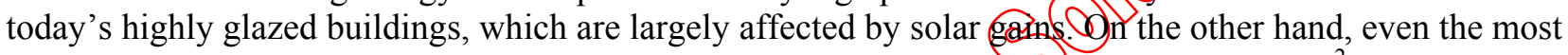
advanced models deviate significantly at specific hourly time steps (uned roughly $100 \mathrm{~W} / \mathrm{m}^{2}$ ), which poses serious limitations to accuracy of predictions of cooling power at specific point in time, the short-time temperature fluctuations in the case of non-air conditioned buildingss or the control and/or sizing of HVAC equipment or shading devices. When performing building simulations, engineers must consider much higher uncertainties at specific time steps.

Additional factors that were not investigated inefude the number of components of solar irradiance measured at a given weather station (often only global houfontal irradiance is measured and other models are used to compute beam irradiance), locations and densities of the weather stations used as inputs for building simulation codes, and reliability of meatner files used by building energy simulation codes.

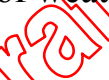

Note: Radiation data and data of ather experiments within the IEA Task 34 project can be downloaded from our website at www.empach/ieatask34. 


\section{Acknowledgements}

We gratefully acknowledge with thanks the financial support from the Swiss Federal Office of Energy (BFE) for building and testing the experimental facility (Project 17'166) as well as the funding for EMPA participation in IEA Task 34/43 (Project 100'765). We would also like to acknowledge Dr. M. Morris from the Iowa State University Statistics Department for his clear direction with regard to formulating the sensitivity analysis and the many contributions from our colleagues R. Blessing, S. Carl, M. Camenzind, T. Frank and R. Vonbank.

\section{References}

Aude, P., Tabary, L., and Depecker, P., 2000. Sensitivity analysis and validation of buildings' thermal models using adjoint-code method. Energy and Buildings 30:267-283

Badascu, V., 2002. 3D Isotropic approximation for solar diffuse irradiance on tilted surfaces. Renewable Energy 26:221-233

Behr, H.D.,1997. Solar radiation on tilted south oriented surfaces: validation of transfer-models. Solar Energy Vol. 61 No.6:399-413

Buehl, F., 2005. Private email correspondence exchanged on March 9, 2005 with Peter Loutzenhiser at EMPA that contained the radiation model portion of the DOE-2.1E source code, LBNL

DOE-2.1E (Version-119). 2002. Building Energy Simulation Code, Lawrence Berkley Laboratories (LBL), Berkley, CA, April 9, 2002

Duffie, J.A., and Beckman, W.A., 1991. Solar Engineering of Thermal Processes $2^{\text {nd }}$ Edition, John Wiley \& Sons, New York, Chichester, Brisbane, Toronto, Singapore

EnergyPlus Version 1.2.2.030. 2005. Building Energy simulation code, www.energyplus.gov

ESP-r, Version 10.12, 2005, University of Strathclyde, www.esru.strath.ac.uk.

European Standard EN 410, 1998. Glass in building - Determination of luminous and solar characteristics of glazing. European Committee for Standardization, Brussels, Belgium

Fishman, G.S., 2000. Monte Carlo: Concepts, Algorithms, and Applications, Springer, New York, Berlin, Heidelberg

Fürbringer, J.M., and Roulet, C.A., 1999. Confidence of simulation results: put a sensitivity analysis module in you MODEL: The IEA-ECBCS Annex 23 experience of model evaluation. Energy and Buildings 30:61-71

Fürbringer, J.M., and Roulet, C.A., 1995, Comparison and Combination of Factorial and Monte-Carl Design in Sensitivity Analysis. Building and Environment Vol. 30 No.4:505-519

Hay, J.E., Davies, J.A., 1980. Calculations of the solar radiation incident on an inclined surface, of First Canadian Solar Radiation Data Workshop (Eds: J.E. Hay and T.K. Won), Ministry of Sorpply and Services Canada, 59

Hottel, H.C. and Woetrz, B.B., 1942, Evaluation of flat-plate solar heat collector. Thans. ASME 64, 91

Ineichen, P., Perez, R., and Seals, R., 1987. The importance of correct albeto determination for adequately modeling energy received by a tilted surface. Solar Energy Vol.39 No.4:301-30s

GLAD Software, 2002. EMPA Material Science and Technology, Duebendore suxitzerland

Glesner, J.L., 1998. Assessing Uncertainty in Measurement. Statistica_Scieface Vol. 13 No.3:277-290

Gueymard, C., 1987. An anisotropic solar irradiance model for tiltedsurfaces and its comparison with selected engineering algorithms. Solar Energy Vol.38 No.5:306386

Klein, S.A., 2004. Engineering Equation Solver (EES) Softyare, Department of Mechanical Engineering, University of Wisconsin-Madison

Klucher, T.M, 1979. Evaluation of models to predict insolation on tilted surfaces. Solar Energy 4,14.

Li, D.H.W., Lam, J.C., Lau, and Chris C.S., 2002 (new approach for predicting vertical global solar irradiance. Renewable Energy 25:591-606 
Lomas, K.J. and Eppel, H., 1992. Sensivity analysis techniques for building thermal simulation programs. Energy and Buildings 19:21-44

Macdonald, I. and Strachan, P., 2001. Practical applications of uncertainty analysis. Energy and Buildings, 33:219-227

Mara, T.A., Garde, F., Boyer, H., and Mamode, M., 2001. Empirical validation of the thermal model of a passive solar test cell. Energy and Buildings 33:589-599

MATLAB Version 7.0.0.19920, 2004. The MathWorks Inc.

Manz, H., Loutzenhiser, P., Frank, T., Strachan, P.A., Bundi, R., and Maxwell, G. (Submitted February 2005 to Building and Environment ) Series of experiments for empirical validation of solar gain modeling in building energy simulation codes - Experimental setup, test cell characterization, specifications and uncertainty analysis.

Modest, M., 2003. Radiative Heat Transfer $2^{\text {nd }}$ Edition, Academic Press, Amsterdam.

Muneer, T., 1997. Solar radiation and daylight models for the energy efficient design of buildings, Architectural Press, Oxford.

Olmo, F.J., Vida, J., Castro-Diez, Y., and Alados-Arboledas, L., 1999. Prediction of global irradiance on inclined surfaces from horizontal global irradiance. Energy 24:689-704

Palomo del Barrio, E., and Guyon,G., 2004. Application of parameters space analysis tools fro empirical model validation. Energy and Buildings 36:23-33

Palomo del Barrio, E., and Guyon,G., 2003. Theoretical basis for empirical model validation using parameter space analysis tools. Energy and Buildings 35:985-996

Perez, R., Stewart, R., Arbogast, C., Seals, R., and Scott, J., 1986. An anisotropic hourly diffuse radiation model for sloping surfaces: Description, performance validation, site dependency evaluation. Solar Energy Vol.36 No.6:481-497

Perez, R., Seals, R., Ineichen, P., Stewart, R., and Menicucci D., 1987. A new simplified version of the Perez diffuse irradiance model for tilted surfaces. Solar Energy Vol.39 No.3:221-232

Perez, R., Stewart r., Seals, R., and Guertin, T. 1988. The development and verification of the Perez diffuse radiation model. Sandia National Laboratories Contractor Report SAND88-7030

Perez, R., Ineichen, P., Seals, R., Michalsky, J., and Stewart, R., 1990. Modeling daylight availability and irradiance components from direct and global irradiance. Solar Energy Vol.44 No.5:271-289

Reindl, D.T., Beckmann, W.A., Duffie, J.A., 1990a. Diffuse fraction correlations. Solar Energy 45:1-7

Reindl, D.T., Beckmann, W.A., Duffie, J.A., 1990b. Evaluation of hourly tilted surface radiation models. Solar Energy 45:9-17

Remund, J., Salvisberg, E., and Kunz, S.,1998. On the generation of hourly shortwave radiation data on tilted surfaces. Solar Energy Vol.62 No.5:331-334

Robledo, L. and Solar, A., 2002. A simple clear skies model for the luminous efficacy of diffuse solar radiation on inclined surfaces. Renewable Energy 26:169-176

Rubinstein, R.Y.,1981. Simulation and the Monte Carlo Method, John Wiley \& Sons, New York, Chichester, Brisbane, Toronto

Saltelli, A., Tarantola, S., Campolongo, F., and Ratto, M., 2004. Sensitivity Analysis in Practice. A Guside to Assessing Scientific Models, John Wiley \& Sons, LTD

Saltelli, A., Chan, K., and Scott, E.M., 2000. Sensitivity Analysis, John Wiley \& Sons, 1 thy hester, New York, Weinheim, Brisbane, Singapore, Toronto

Santner, T.J., Williams, B.J., and Notz, W.I., 2003. The Design and Analysis ofCemputer Experiments, Springer, New York, Berlin, Heidelberg

TRNSYS-TUD, 2005, Technical University of Dresden research code based on the frame of TRNSYS 14.2, Solar Energy Laboratory, University of Wisconsin-Madison, Madisen, ㄲ, 1996

Vardeman, S.B., and Jobe, J.M., 2001. Data Collection and Analyssis, (D) yxxbury Thomson Learning, Australia, Canada, Mexico, Singapore, Spain, United Kingdom, United States 
Table 1 Instruments used for measuring solar irradiance.

\begin{tabular}{|c|c|c|c|c|}
\hline Parameter & Unit & Type of sensor / measurement & $\begin{array}{l}\text { Number of } \\
\text { sensors }\end{array}$ & Accuracy \\
\hline $\begin{array}{l}\text { Solar global irradiance, façade } \\
\text { plane }\left(29^{\circ} \mathrm{W} \text { of S) }\right.\end{array}$ & $\mathrm{W} / \mathrm{m}^{2}$ & Pyranometer (Kipp \& Zonen CM 21) & 1 & $\pm 2 \%$ \\
\hline $\begin{array}{l}\text { Solar global horizontal } \\
\text { irradiance }\end{array}$ & $\mathrm{W} / \mathrm{m}^{2}$ & Pyranometer (Kipp \& Zonen CM 21) & 1 & $\pm 2 \%$ \\
\hline $\begin{array}{l}\text { Solar diffuse horizontal } \\
\text { irradiance }\end{array}$ & $\mathrm{W} / \mathrm{m}^{2}$ & $\begin{array}{l}\text { Pyranometer, mounted under the } \\
\text { shading ball of a tracker (Kipp \& } \\
\text { Zonen CM 11) }\end{array}$ & 1 & $\pm 3 \%$ \\
\hline Direct-normal irradiance & $\mathrm{W} / \mathrm{m}^{2}$ & $\begin{array}{l}\text { Pyrheliometer, mounted in an } \\
\text { automatic sun-following } \\
\text { tracker(Kipp \& Zonen CH 1) }\end{array}$ & 1 & $\pm 2 \%$ \\
\hline
\end{tabular}

Table 2 Solar ground reflectance.

\begin{tabular}{lc}
\hline Parameter & Reflectance, \% \\
\hline Hemispherical-Hemispherical & $14.8 \pm 0.74$ \\
Near Direct Normal-Hemispherical & 8.8 \\
\hline
\end{tabular}

Table 3 Average factorial impacts $\left(\alpha_{S}>0\right)$.

\begin{tabular}{ccccc}
\hline & \multicolumn{2}{c}{ Period 1 } & \multicolumn{2}{c}{ Period 2 } \\
\cline { 2 - 5 } Factorial & $\begin{array}{c}\text { Forward } \\
\text { Differencing, } \\
\text { W/m }\end{array}$ & $\begin{array}{c}\text { Backward } \\
\text { Differencing, } \\
\text { W/m }{ }^{2}\end{array}$ & $\begin{array}{c}\text { Forward } \\
\text { Differencing, } \\
\text { W/m }\end{array}$ & $\begin{array}{c}\text { Backward } \\
\text { Differencing, } \\
\text { W/m }\end{array}$ \\
\hline$I_{b n}$ & 1.13 & -1.10 & 1.23 & -1.31 \\
$I_{h, d}$ & 1.37 & -1.28 & 1.50 & -1.59 \\
$\rho$ & 0.357 & -0.357 & 0.566 & -0.566 \\
$\phi_{b}$ & -0.499 & 0.500 & -0.291 & 0.303 \\
$I_{b n} \times I_{h, d}$ & -0.05596 & -0.0831 & 0.0663 & 0.0531 \\
$I_{b n} \times \rho$ & 0.00155 & 0.00158 & 0.00308 & 0.00310 \\
$I_{b n} \times \phi_{b}$ & -0.00464 & -0.00464 & -0.0027 & -0.00274 \\
$I_{h, d} \times \rho$ & 0.00352 & 0.00380 & 0.00514 & 0.00516 \\
$I_{h, d} \times \phi_{b}$ & -0.00267 & -0.00264 & -0.00094 & -0.000907 \\
$\rho \times \phi_{b}$ & No & No & No & No \\
$u$ & Interactions & Interactions & Interactions & Interaction \\
\hline
\end{tabular}


Table 4 Analysis of global vertical façade irradiance in $\mathrm{W} / \mathrm{m}^{2}\left(\alpha_{S}>0\right)$ for Period 1.

\begin{tabular}{|c|c|c|c|c|c|c|c|c|c|c|c|c|}
\hline & 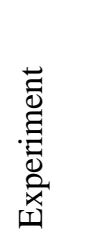 & 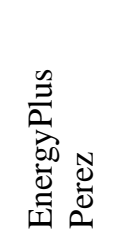 & 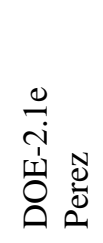 & 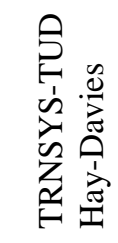 & 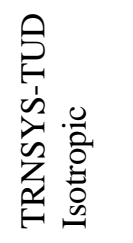 & 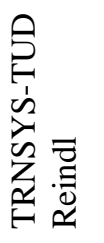 & 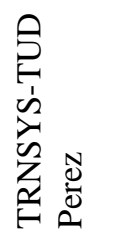 & 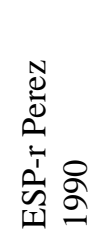 & 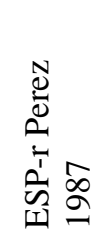 & 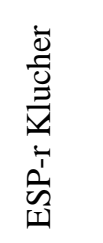 & 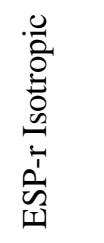 & 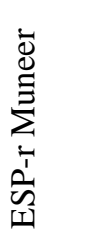 \\
\hline $\bar{x}$ & 176.1 & 169.7 & 177.2 & 165.1 & 157.8 & 170.9 & 169.8 & 188.2 & 192.8 & 174.8 & 171.9 & 191.4 \\
\hline$s$ & 223.8 & 211.8 & 218.6 & 205.1 & 190.1 & 209.4 & 211.1 & 218.2 & 220.5 & 196.9 & 192.5 & 226.3 \\
\hline$x_{\max }$ & 856.8 & 817.8 & 820.4 & 801.2 & 743.2 & 810.4 & 796.4 & 804.7 & 806.7 & 743.5 & 728.8 & 915.7 \\
\hline$x_{\min }$ & 0.2 & 0.3 & 0.0 & 0.4 & 0.9 & 0.4 & 0.3 & 0.2 & 0.1 & 0.3 & 0.3 & 0.2 \\
\hline $\bar{D}$ & - & -6.4 & 1.1 & -11.0 & -18.3 & -5.2 & -6.3 & 1.9 & 6.6 & -11.5 & -14.3 & 5.1 \\
\hline$\overline{|D|}$ & - & 13.7 & 10.5 & 18.0 & 26.2 & 15.7 & 11.7 & 13.3 & 14.7 & 24.6 & 27.8 & 14.1 \\
\hline$D_{\max }$ & - & 103.5 & 67.1 & 108.0 & 138.9 & 90.4 & 73.3 & 87.7 & 86.7 & 139.1 & 157.7 & 205.5 \\
\hline$D_{\min }$ & - & 0.0 & 0.0 & 0.0 & 0.0 & 0.0 & 0.0 & 0.0 & 0.0 & 0.0 & 0.0 & 0.0 \\
\hline$D_{r m s}$ & - & 24.2 & 17.0 & 28.9 & 44.4 & 24.0 & 21.0 & 21.4 & 22.1 & 39.1 & 44.7 & 24.6 \\
\hline$D_{95 \%}$ & - & 56.4 & 40.3 & 71.7 & 111.2 & 56.3 & 57.1 & 50.9 & 51.5 & 96.5 & 110.7 & 53.3 \\
\hline$\overline{O U}$ & 6.90 & 4.62 & - & - & - & - & - & - & - & - & - & - \\
\hline$\overline{U R}$ & - & 1.34 & 1.34 & 2.28 & 4.03 & 2.29 & 1.12 & 1.43 & 1.69 & 2.50 & 2.63 & 1.54 \\
\hline$U R_{\max }$ & - & 12.42 & 20.41 & 20.41 & 129.05 & 20.41 & 10.20 & 11.22 & 12.09 & 17.04 & 17.04 & 13.48 \\
\hline$U R_{\min }$ & - & 0.00 & 0.01 & 0.00 & 0.00 & 0.00 & 0.00 & 0.00 & 0.00 & 0.01 & 0.00 & 0.00 \\
\hline$\overline{|D|} / \bar{x}$ & - & 7.8 & 5.9 & 10.2 & 14.9 & 8.9 & 6.7 & 6.7 & 6.7 & 14.8 & 16.7 & 7.2 \\
\hline $\bar{D} / \bar{x}$ & - & -3.7 & 0.6 & -6.2 & -10.4 & -3.0 & -3.6 & -2.7 & -0.1 & -11.3 & -13.4 & 1.0 \\
\hline
\end{tabular}

Table 5 Analysis of global vertical façade irradiance in $\mathrm{W} / \mathrm{m}^{2}\left(\alpha_{S}>0\right)$ for Period 2.

\begin{tabular}{|c|c|c|c|c|c|c|c|c|c|c|c|c|}
\hline & 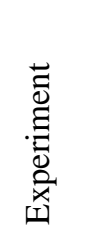 & 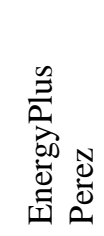 & 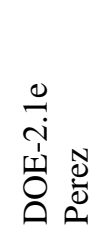 & 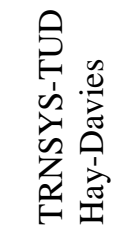 & 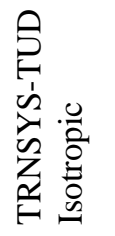 & 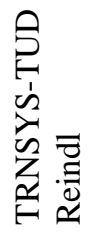 & 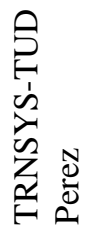 & 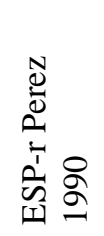 & 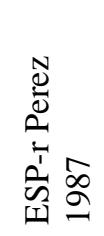 & 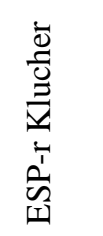 & 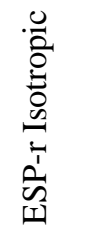 & 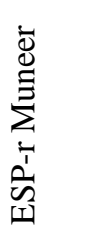 \\
\hline $\bar{x}$ & 194.5 & 208.5 & 210.5 & 199.7 & 191.6 & 207.7 & 201.4 & 202.0 & 206.7 & 190.1 & 187.9 & 202.5 \\
\hline$S$ & 222.1 & 226.3 & 231.3 & 219.0 & 201.5 & 224.1 & 225.2 & 222.4 & 223.8 & 201.3 & 197.3 & 224.2 \\
\hline$x_{\max }$ & 797.1 & 796.3 & 828.5 & 807.8 & 741.4 & 820.2 & 801.7 & 794.6 & 799.5 & 730.4 & 720.2 & 801.1 \\
\hline$x_{\min }$ & 0.3 & 0.3 & 0.0 & 0.4 & 0.4 & 0.4 & 0.3 & 0.2 & 0.2 & 0.3 & 0.3 & 0.2 \\
\hline $\bar{D}$ & - & 14.0 & 16.0 & 5.2 & -2.9 & 13.2 & 6.9 & 7.5 & 12.2 & -4.4 & -6.6 & 8.0 \\
\hline$\overline{|D|}$ & - & 19.4 & 17.6 & 16.2 & 25.0 & 19.0 & 12.7 & 14.6 & 17.2 & 23.4 & 26.4 & 15.4 \\
\hline$D_{\max }$ & - & 104.0 & 77.3 & 59.5 & 122.6 & 67.2 & 63.5 & 81.3 & 86.7 & 113.0 & 134.9 & 86.9 \\
\hline$D_{\min }$ & - & 0.0 & 0.1 & 0.1 & 0.1 & 0.1 & 0.0 & 0.0 & 0.0 & 0.0 & 0.0 & 0.0 \\
\hline$D_{r m s}$ & - & 29.2 & 26.3 & 20.9 & 35.2 & 24.5 & 19.2 & 22.2 & 24.5 & 33.6 & 38.8 & 24.0 \\
\hline$D_{95 \%}$ & - & 70.1 & 62.4 & 42.6 & 81.7 & 51.1 & 46.3 & 50.9 & 58.0 & 79.9 & 93.2 & 55.6 \\
\hline$\overline{O U}$ & 7.62 & 5.62 & - & - & - & - & - & - & - & - & - & - \\
\hline$\overline{U R}$ & - & 2.11 & 2.12 & 2.66 & 3.06 & 2.99 & 1.41 & 1.61 & 2.00 & 2.60 & 2.73 & 1.64 \\
\hline$U R_{\max }$ & - & 12.83 & 21.70 & 20.62 & 20.63 & 21.41 & 11.21 & 9.70 & 11.24 & 14.94 & 14.94 & 13.48 \\
\hline$U R_{\min }$ & - & 0.00 & 0.02 & 0.01 & 0.03 & 0.01 & 0.01 & 0.00 & 0.00 & 0.01 & 0.01 & 0.00 \\
\hline$\overline{|D|} / \bar{x}$ & - & 10.0 & 9.1 & 8.3 & 12.9 & 9.8 & 6.5 & 7.5 & 8.8 & 12.0 & 13.6 & 7.9 \\
\hline $\bar{D} / \bar{x}$ & - & 7.2 & 8.2 & 2.7 & -1.5 & 6.8 & 3.5 & 3.9 & 6.3 & -2.3 & -3.4 & 4.1 \\
\hline
\end{tabular}


Table 6 Analysis of global vertical façade irradiance in $\mathrm{W} / \mathrm{m}^{2}\left(\alpha_{S}>0\right)$ for both periods.

\begin{tabular}{|c|c|c|c|c|c|c|c|c|c|c|c|c|}
\hline & 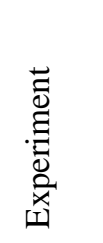 & 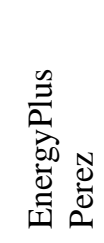 & 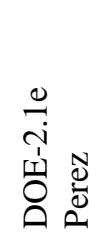 & 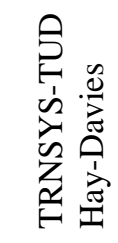 & 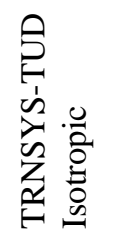 & 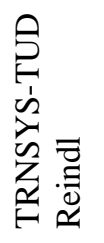 & 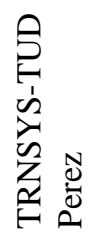 & 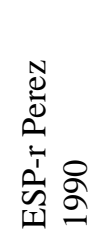 & 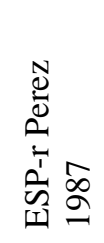 & 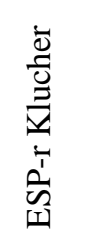 & 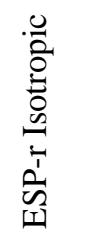 & 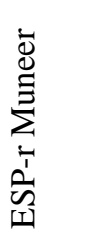 \\
\hline $\bar{x}$ & 186.2 & 191.0 & 195.5 & 184.1 & 176.3 & 191.1 & 187.1 & 188.2 & 192.8 & 174.8 & 171.9 & 191.4 \\
\hline$S$ & 222.9 & 220.6 & 226.1 & 213.4 & 197.0 & 218.2 & 219.4 & 218.2 & 220.5 & 196.9 & 192.5 & 226.3 \\
\hline$x_{\max }$ & 856.8 & 817.8 & 828.5 & 807.8 & 743.2 & 820.2 & 801.7 & 804.7 & 806.7 & 743.5 & 728.8 & 915.7 \\
\hline$x_{\min }$ & 0.2 & 0.3 & 0.0 & 0.4 & 0.4 & 0.4 & 0.3 & 0.2 & 0.1 & 0.3 & 0.3 & 0.2 \\
\hline $\bar{D}$ & - & 4.8 & 9.3 & -2.1 & -9.9 & 4.9 & 0.9 & 1.9 & 6.6 & -11.5 & -14.3 & 5.1 \\
\hline$\overline{|D|}$ & - & 16.8 & 14.4 & 17.0 & 25.6 & 17.5 & 12.2 & 13.3 & 14.7 & 24.6 & 27.8 & 14.1 \\
\hline$D_{\max }$ & - & 104.0 & 77.3 & 108.0 & 138.9 & 90.4 & 73.3 & 87.7 & 86.7 & 139.1 & 157.7 & 205.5 \\
\hline$D_{\min }$ & - & 0.0 & 0.0 & 0.0 & 0.0 & 0.0 & 0.0 & 0.0 & 0.0 & 0.0 & 0.0 & 0.0 \\
\hline$D_{r m s}$ & - & 27.1 & 22.6 & 24.8 & 39.6 & 24.3 & 20.0 & 21.4 & 22.1 & 39.1 & 44.7 & 24.6 \\
\hline$D_{95 \%}$ & - & 65.7 & 55.1 & 54.9 & 99.4 & 54.2 & 48.7 & 50.9 & 51.5 & 96.5 & 110.7 & 53.3 \\
\hline$\overline{O U}$ & 7.30 & 4.46 & - & - & - & - & - & - & - & - & - & - \\
\hline$\overline{U R}$ & - & 1.91 & 1.90 & 2.57 & 3.61 & 2.77 & 1.38 & 1.43 & 1.69 & 2.50 & 2.63 & 1.54 \\
\hline$U R_{\max }$ & - & 17.62 & 29.31 & 28.31 & 129.05 & 29.39 & 15.38 & 11.22 & 12.09 & 17.04 & 17.04 & 13.48 \\
\hline$U R_{\min }$ & - & 0.00 & 0.01 & 0.00 & 0.00 & 0.00 & 0.00 & 0.00 & 0.00 & 0.01 & 0.00 & 0.00 \\
\hline$\overline{|D|} / \bar{x}$ & - & 9.0 & 7.7 & 9.1 & 13.7 & 9.4 & 6.6 & 7.2 & 7.9 & 13.2 & 14.9 & 7.6 \\
\hline $\bar{D} / \bar{x}$ & - & 2.6 & 5.0 & -1.1 & -5.3 & 2.6 & 0.5 & 1.0 & 3.5 & -6.2 & -7.7 & 2.8 \\
\hline
\end{tabular}

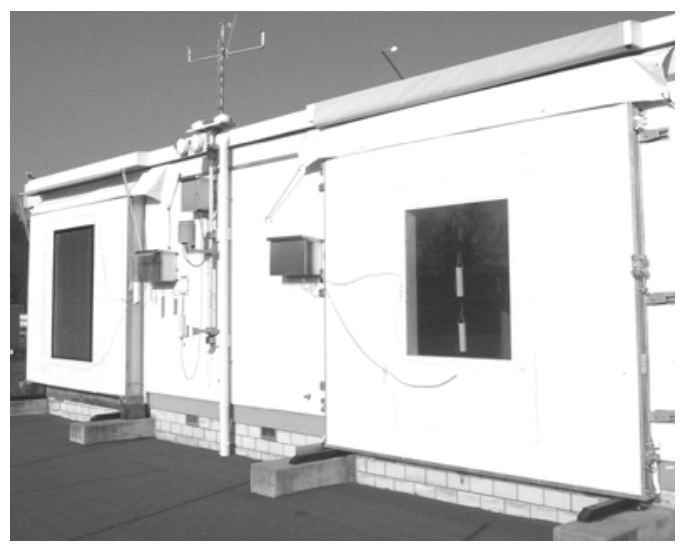

Figure 1 Test cells with pyranometers visible in the central part of the picture and green artificial turf installed in front of the test cell. 


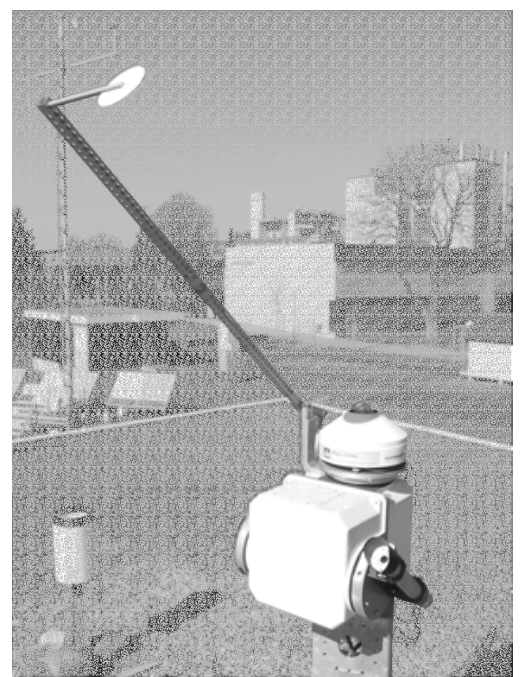

Figure 2 Pyrheliometer for measuring direct-normal and shaded pyranometer for measuring diffuse horizontal solar irradiance are positioned on the roof of the facility.

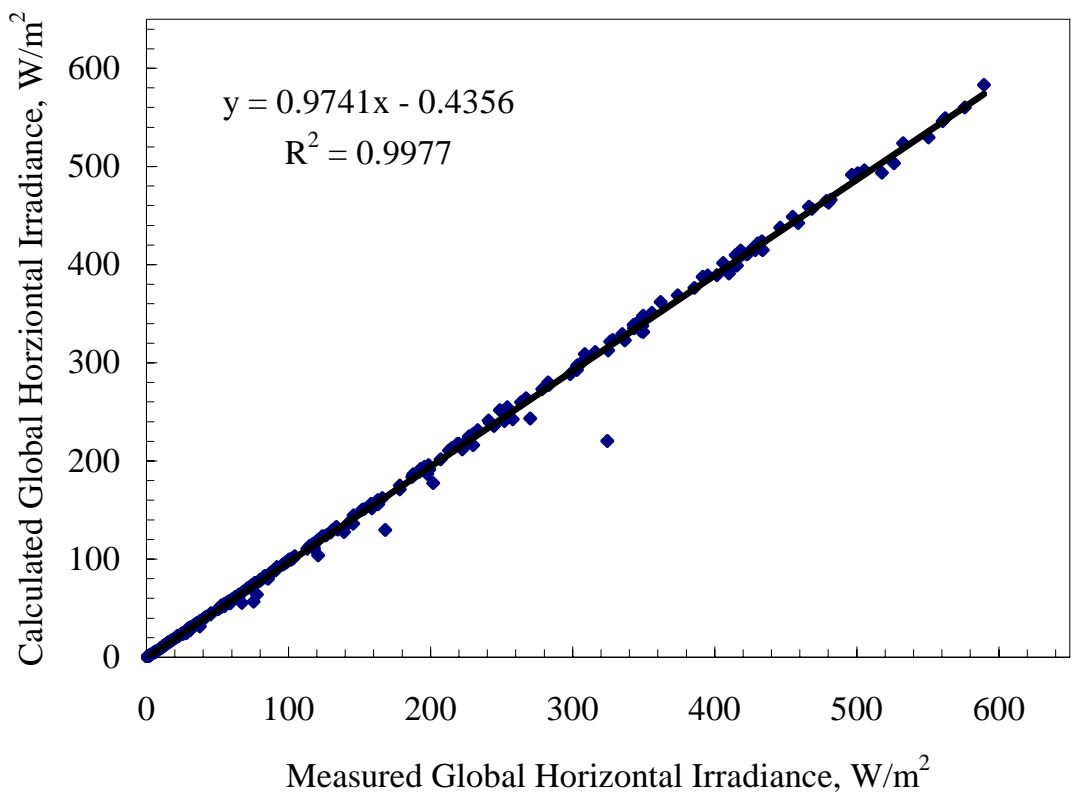

Figure 3a Measured and calculated global horizontal irradiance for Period 1. 


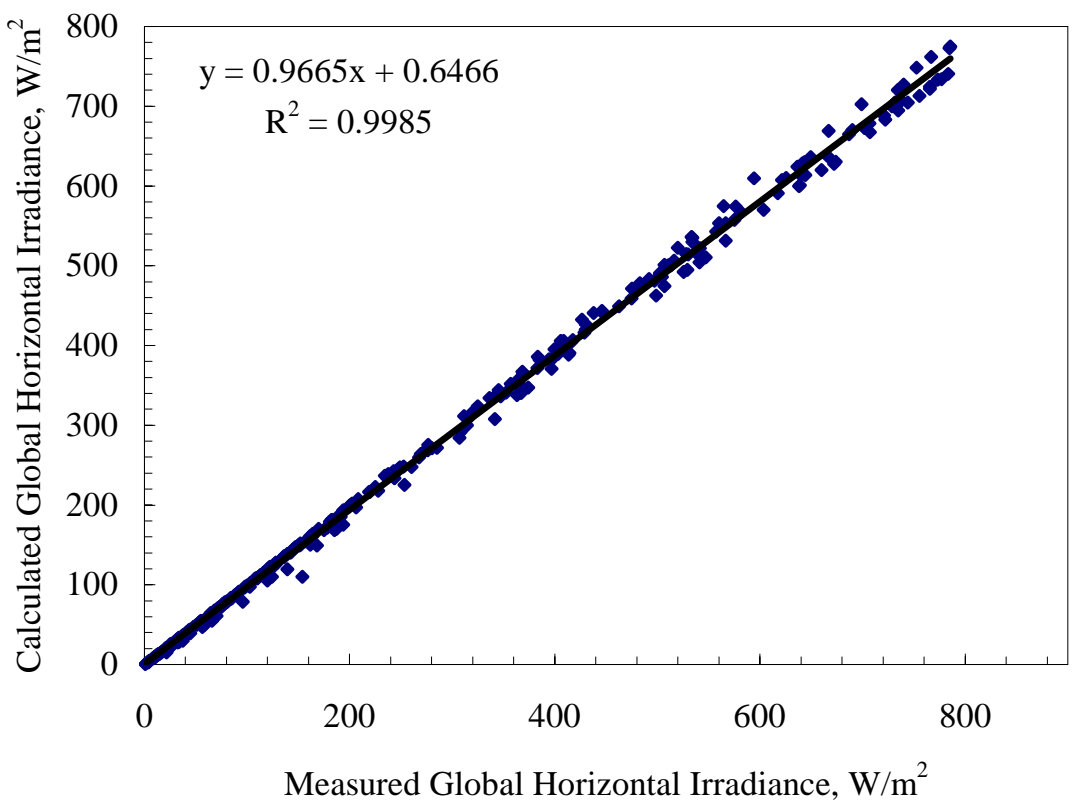

Figure 3b Measured and calculated global horizontal irradiance for Period 2.

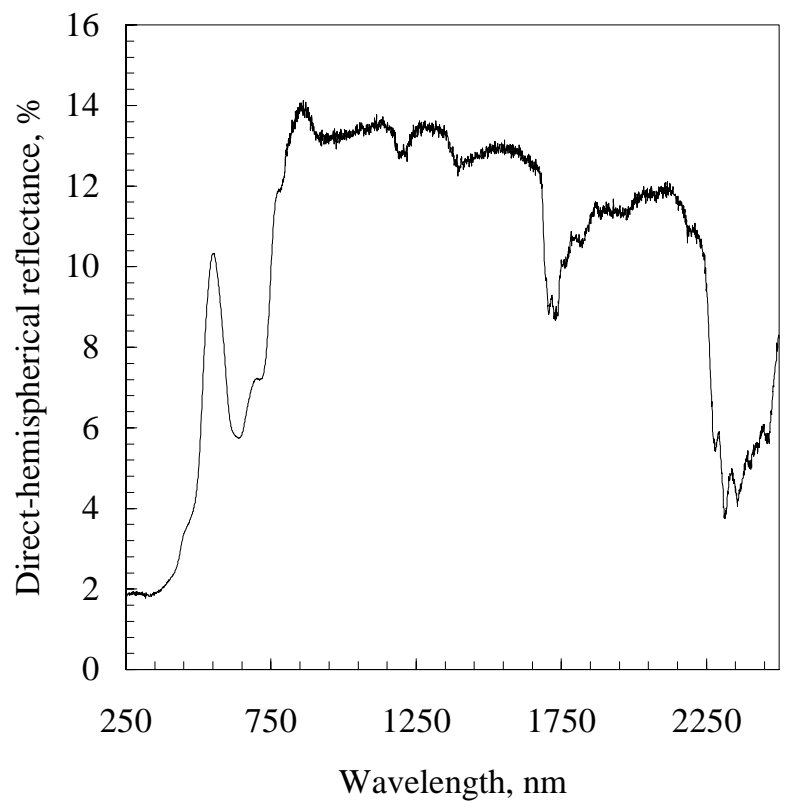

Figure 4 Directional-hemispherical reflectance of the artificial turf. 


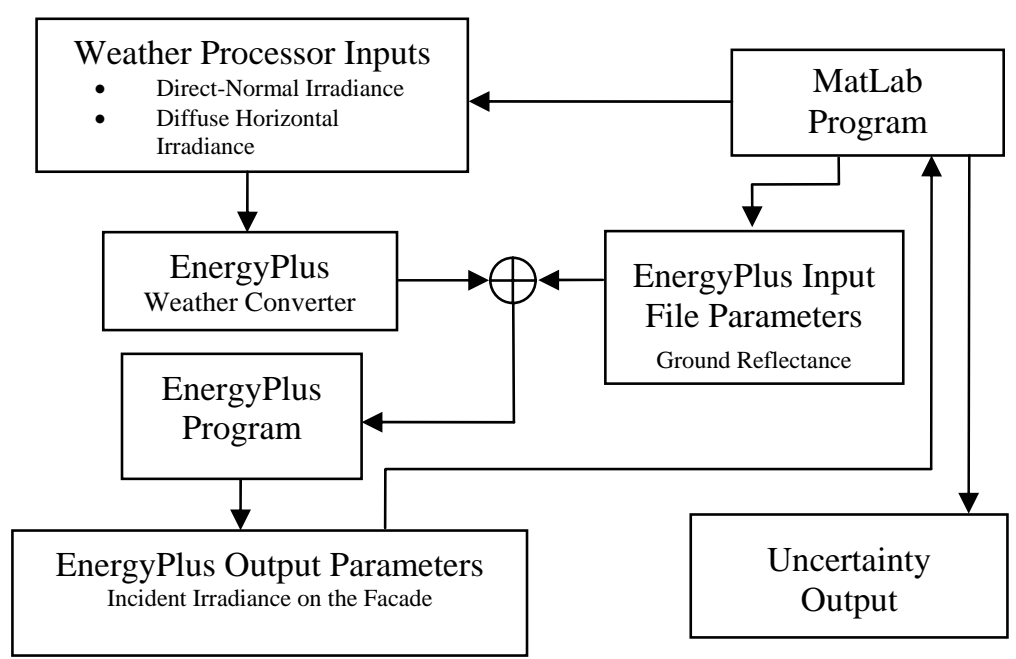

Figure 5 Flowchart for the sensitivity studies. 


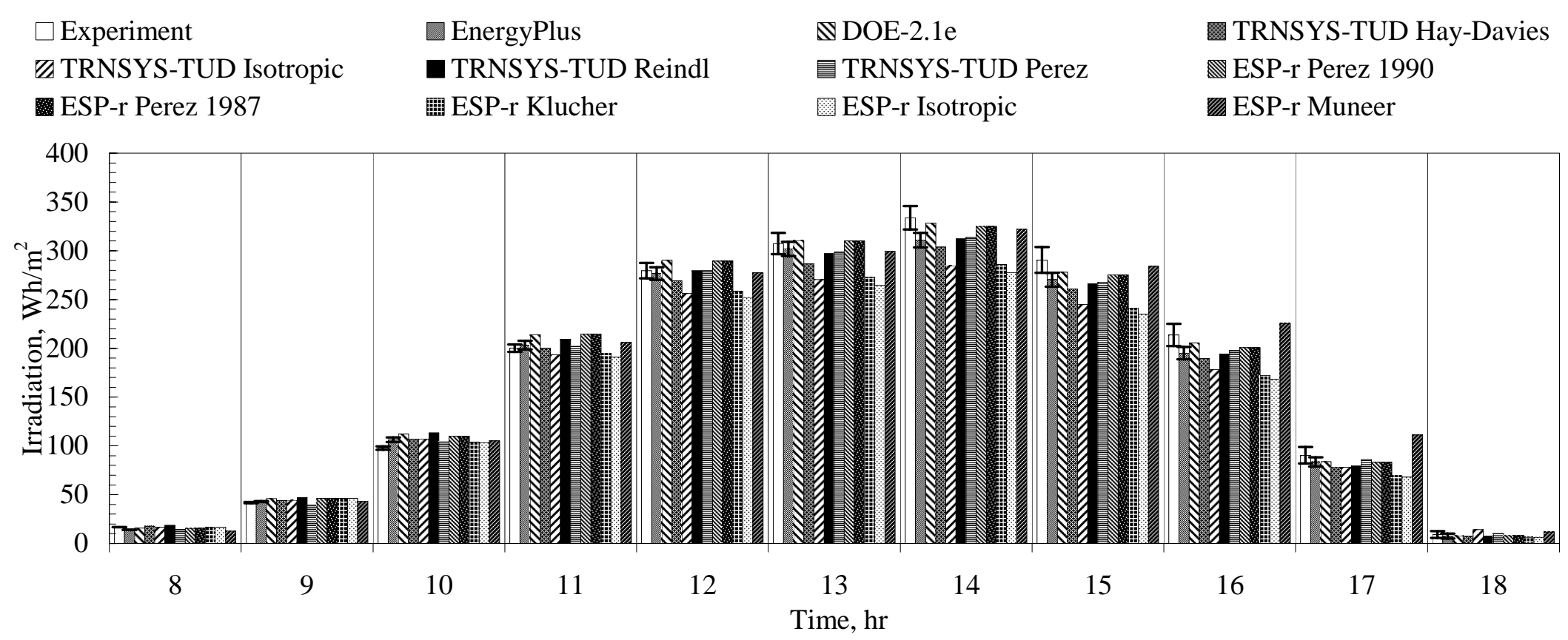

Figure 6 Average hourly irradiation comparisons for the vertical façade for Period 1. 


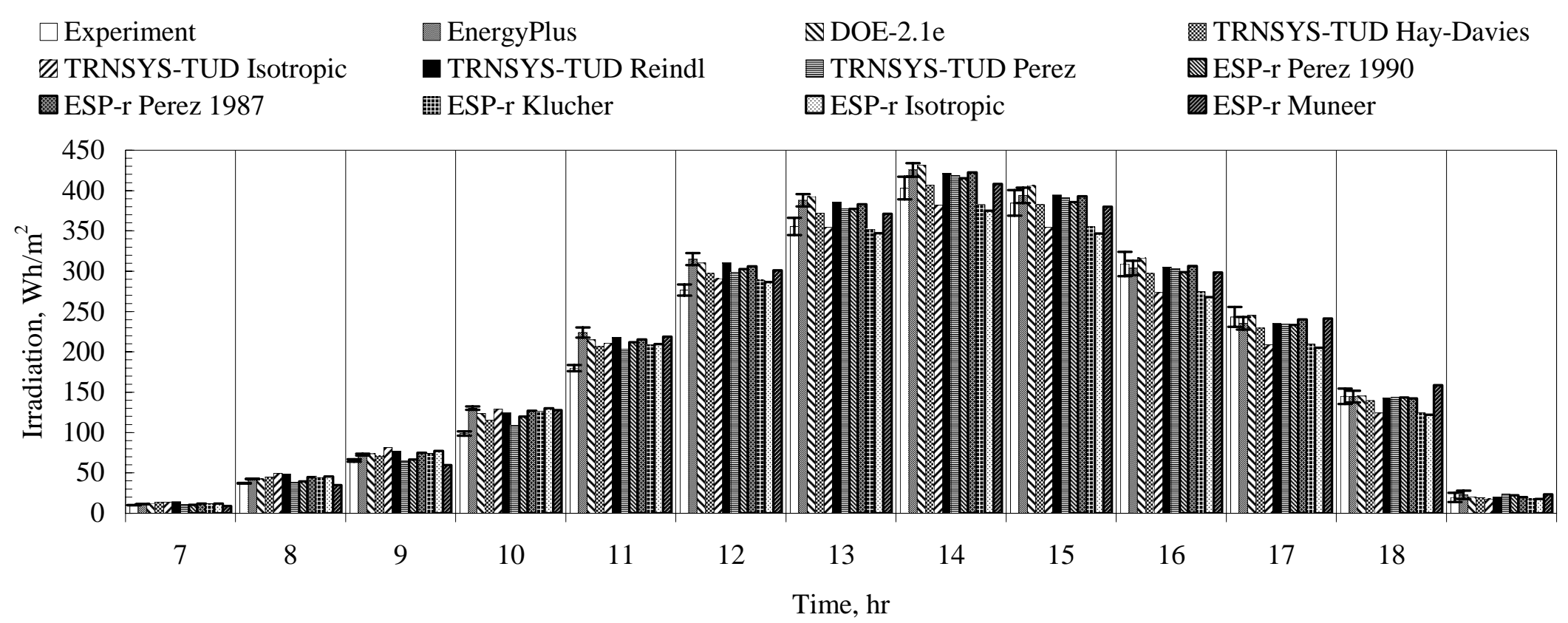

Figure 7 Average hourly irradiation comparisons for the vertical façade for Period 2. 


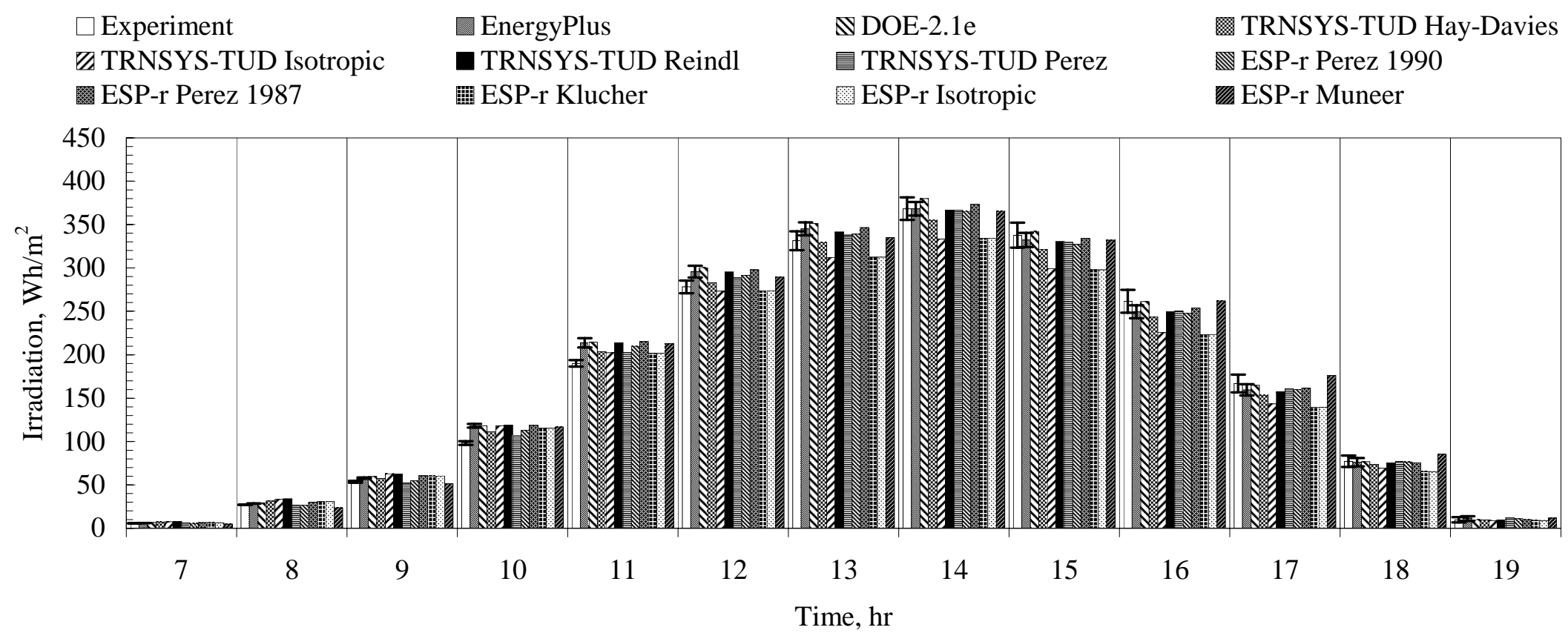

Figure 8 Average hourly irradiation comparisons for the vertical façade combining both periods. 